\title{
Influence of cenosphere particles on thermal properties composites of silicon rubber
}

\author{
Przemysław Rybiński $^{1}$ - Witold Żukowski ${ }^{2} \cdot$ Dariusz Bradło $^{2}$
}

Received: 26 March 2015 / Accepted: 2 June 2015/Published online: 25 June 2015

(c) The Author(s) 2015. This article is published with open access at Springerlink.com

\begin{abstract}
The study presents the investigation results concerning the thermal properties of non-cross-linked and cross-linked silicone rubber with organic peroxide. The rubber was filled with mineral fillers such as cenospheres, including cenospheres covered with iron, attapulgite, wollastonite, aluminum hydroxide and silica. The thermal stability of the silicone rubber was considered from the point of view of the mineral fillers used, particularly taking into account the modern cenospheric filler. Thermal analysis was carried out under both air and a neutral gas at temperatures ranging from 120 to $700{ }^{\circ} \mathrm{C}$. The activation energy value of the silicone rubber destruction was determined with the use of the non-isothermal method of Flynn-Wall-Ozawa.
\end{abstract}

Keywords Silicone rubber - Cenospheric filler - Thermal stability $\cdot$ Destruction activation energy

\section{Introduction}

Synthetic polymers are a crucial part of today's life, and they can be found nearly everywhere and more and more frequently and faster replace conventional materials such as metal, ceramics or wood. Despite many unquestionable advantages, synthetic polymeric materials also have some limitations, including their flammability $[1,2]$.

Przemysław Rybiński

przemek100@ujk.kielce.pl;

przemyslaw.rybinski@ujk.edu.pl

1 Management of Environment Protection and Modeling, The Jan Kochanowski University, Kielce, Poland

2 Department of Chemical Engineering and Technology, Cracow University of Technology, Kraków, Poland
In accordance with the current legal regulations, the products obtained from synthetic polymers, such as carpets, electric conductors or furniture, must be characterized by a specified resistance to fire.

From the review of source literature, it follows that a considerable improvement in fire resistance of polymeric materials can be obtained with the use of polysiloxanes in their production [3-5]. The commercial production of silicone polymers began in 1940. Their production as well as the number of their potential, practical applications has systematically increased for 75 years. It is estimated that in the scale of all the world, the value of the manufacture of silicone materials amounts now to several billion dollars, while all the time, it shows a constant growing trend [4, 6].

From among various silicone materials, the highest industrial importance has silicone rubbers (SR). These consist of the main chain built-up from alternately arranged silicon and oxygen atoms, to which are connected organic groups. Most often these are methylene groups with a possible low number of vinyl groups that make the radical cross-linking easier [7].

Because of its specific chemical structure, polysiloxanes are characterized by several unique properties including a high elasticity, electric resistance as well as biocompatibility, constancy of physical and mechanical properties within a very wide temperature range and also a high resistance to external heat sources. In the case of most polysiloxanes, the value of their maximal heat release rate $\left(H R R_{\max }\right)$ ranges from 60 to $150 \mathrm{~kW} \mathrm{~m}{ }^{-2}[3,4]$.

Contrary to organic polymers, during the thermal decomposition of silicones, especially in the presence of oxygen, there appears inorganic silica with a high heat capacity. The effectiveness of the fuel diffusion to flame and oxygen to the sample surface depends first off all on the structure of boundary layer, whose insulating properties 
considerably depend on the integrity occurred during the thermal decomposition of polysiloxane silica layer.

From the review of source literature, it follows that the forces of cohesive interactions between silica particles resulted from the thermal decomposition of silicones are insufficient to make a condensed boundary layer. The silica formed occurs in the form of dust with a low barrier capability that additionally can be easily removed from the surface of boundary layer through the action of gas stream within the combustion zone [4].

In order to improve the thermal and mechanical properties of polysiloxanes, as well as a reduction in their flammability, these polymers are combined with active fillers [8].

The mutual interaction of active filler particles and the immobilization of polysiloxane macromolecules on their surface that results from physicochemical interactions between the polymer macromolecules and chemically, energetically or sterically active spots on the filler surface, cause the formation of a strongly developed three-dimensional spatial network that penetrating the whole polymer volume significantly improves their thermal and mechanical properties.

The most frequently used mineral filler of silicone rubbers is amorphous silica $[9,10]$. However, it should be noticed that precipitated silica, especially non-hydrophobized silica, contains at the average $5-8 \%$ by mass of physically combined water. With increasing temperature, liberated water molecules catalyze, so the splitting of polysiloxane chain consequently leads to decreasing the thermal stability of composites filled with it [11].

Potentially, a significant improvement in the thermal properties of silicone rubber and a reduction in their flammability can be obtained by filling them with cenospheric filler.

Cenospheres are alumina silicate particles in the form of thin-walled microspheres with a regular structure. On account of their considerable resistance and excellent mechanical parameters, more and more frequently cenospheres are used as fillers of polymeric materials [12].

In the first part of the paper, the effect of cenospheres on the thermal properties of silicone rubber vulcanizates was compared in relation to conventional mineral fillers such as silica, attapulgite, wollastonite and aluminum hydroxide. In the second part, the effect of the mineral fillers used on the flammability and ceramization capability of silicone rubber composites was presented.

\section{Methods}

\section{Materials}

The object of studies was methylvinylsilicone rubber (MVSR), made by "Silikony Polskie," with a molecular mass of $60-70 \times 10^{4}\left(\mathrm{~kg} \mathrm{~mole}^{-1}\right)$ and vinyl group content of $0.05-0.09 \%\left(\mathrm{~mol} \mathrm{~mole}^{-1}\right)$. The rubber was cross-linked with the use of dicumyl peroxide in a quantity of one part by mass/100 parts by mass of the rubber.

As fillers of the rubber blend, there were used the following compounds: aluminum hydroxide (POCH Gliwice), wollastonite FW 635 , with an average particle size of $3.5 \mu \mathrm{m}$, and a specific surface of $3.25 \mathrm{~m}^{2} \mathrm{~g}^{-1}$ (Nordkalk Corporation), attapulgite, Bentonit SWDC (BDC Polska), anhydrous silica, Aerosil 380, with a specific surface of $380 \mathrm{~m}^{2} \mathrm{~g}^{-1}$ (Evonik Degussa), and cenosphere and cenosphere coated with iron. The mineral fillers were incorporated into the silicone rubber matrix in a quantity of 40 parts by mass $/ 100$ parts by mass of the rubber.

\section{Preparation of cenospheres}

Cenospheres, a waste material in the process of hard coal combustion, were obtained from the heat and power generation plant in Połaniec. These were subjected to initial drying at a temperature of $105^{\circ} \mathrm{C}$ for $12 \mathrm{~h}$ and then purification to remove fine, porous and crushed particles through the hydrothermal process at a temperature of $90{ }^{\circ} \mathrm{C}$ for $30 \mathrm{~min}$. Further, the material obtained in this way was divided into narrow grain fraction, including a $125-160 \mu \mathrm{m}$ that was used in this work. Additionally, some microspheres were coated with iron derived from iron carbonyl by the FB-MOCVD method (fluidized-bed metal-organic chemical vapor deposition), using a laboratory fluidization reactor (Fig. 1). At a temperature of

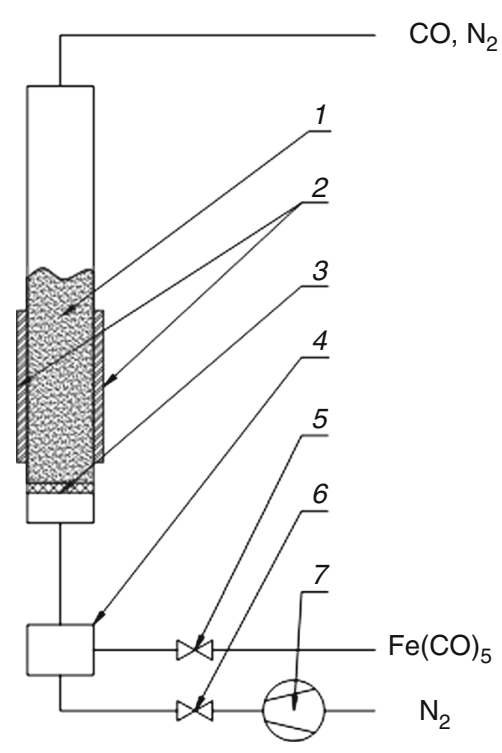

Fig. 1 Scheme of test stand to covered cenospheres by the metallic iron in the fluidized bed. 1 Cenospheres layer, 2 external heat source, 3 distributor, 4 nozzle, 5 control valve of liquid $\mathrm{Fe}(\mathrm{CO})_{5}, 6$ control valve of carrier gas, 7 downcast ventilator 
$190{ }^{\circ} \mathrm{C}$ and with a dose of $0.25 \mathrm{~mL} \mathrm{~g}^{-1}$ of microspheres, a coating of metallic iron with a thickness of about $0.3 \mu \mathrm{m}$ was obtained.

\section{Methods}

\section{SEM analysis}

Microscopic photographs were obtained by means of scanning electron microscope (SEM), model TM3000 from Hitachi model TM3000.

\section{Preparation of rubber blends and their vulcanization}

Silicone rubber blends were prepared at room temperature with the use of a laboratory rolling mill with roll dimensions: $D=150 \mathrm{~mm}, L=300 \mathrm{~mm}$. The rotational speed of the front roll was $20 \mathrm{rpm}$, friction 1:1.

The blends were vulcanized in steel molds placed between the electrically heated press shelves. The optimal vulcanization time $(\tau 0.9)$ at a temperature of $160{ }^{\circ} \mathrm{C}$ was determined by means of a WG vulcameter, according to standard PN-ISO 3417:1994.

\section{Thermal properties of rubber and its vulcanizates}

The thermal properties of the rubber and its cross-linked blends were tested under air and neutral gas at temperatures ranging from 25 to $700{ }^{\circ} \mathrm{C}$, with the use of a Jupiter STA 449 F3 thermal analyzer from Netzsch Company. Weighed portions amounted to 5-10 mg. Samples were analyzed with heating rates $2,5,10,15$ and $20{ }^{\circ} \mathrm{C} \mathrm{min}^{-1}$.

Thermal analysis under nitrogen at -120 to $500{ }^{\circ} \mathrm{C}$ of both the rubber and its cross-linked blends was carried out by means of differential scanning calorimetry, using a DSC-204 thermal analyzer from Netzsch Company, and weighed portions from 5 to $7 \mathrm{mg}$ and a heating rate of $10{ }^{\circ} \mathrm{C} \min ^{-1}$.

\section{Determination of activation energy of destruction investigated rubber}

In general, the thermal degradation reaction of a solid polymer can be simply shown as: $\mathrm{B}_{\text {solid }} \rightarrow \mathrm{C}_{\text {solid }}+\mathrm{D}_{\text {gas }}$, where $\mathrm{B}_{\text {solid }}$ is the starting material, $\mathrm{D}_{\text {gas }}$ and $\mathrm{C}_{\text {solid }}$ are the different products during the disappearance of $\mathrm{B}_{\text {solid. }}$ In thermogravimetric measurements, the degree of decomposition (conversion) can be calculated as follows [13]:

$X=\frac{W_{0}-W_{\mathrm{t}}}{W_{0}-W_{\mathrm{f}}}$

where $X$ is degree of decomposition; $W_{\mathrm{t}}, W_{0}$ and $W_{\mathrm{f}}$ are the actual, initial and final of the mass of the sample, respectively. A typical model for kinetic process can be expressed as:

$\frac{\mathrm{d} X}{\mathrm{~d} t}=k f(X)$

where $\mathrm{d} x / \mathrm{d} t$ is the decomposition rate, $f(X)$, the function of $X$, depends on the particular decomposition mechanism. And $\mathrm{k}$ is the decomposition rate constant, which can be expressed by the Arrhenius equation:

$k=A \exp \left(\frac{-E}{R T}\right)$

where $A$ is the pre-exponential factor $\left(\mathrm{s}^{-1}\right), E$ is the activation energy $\left(\mathrm{J} \mathrm{mol}^{-1}\right), \quad R$ is the gas constant (8.314 $\mathrm{J} \mathrm{mol}^{-1} \mathrm{~K}^{-1}$ ), and $T$ is Kelvin temperature $(\mathrm{K})$. Substituting Eq. (3) into Eq. (2), we obtain

$\frac{\mathrm{d} X}{\mathrm{~d} t}=A \exp \left(\frac{-E}{R T}\right) f(X)$

If the temperature of a sample is changed by a constant value of $\beta(\beta=\mathrm{d} T / \mathrm{d} t)$, the variation of the degree of decomposition can be analyzed as a function of temperature. Therefore, the reaction rate gives:

$\frac{\mathrm{d} X}{\mathrm{~d} T}=\frac{A}{\beta} \exp \left(\frac{-E}{R T}\right) f(X)$

Equations (4) and (5) are the basic equations for the kinetic calculation.

The Flynn-Wall-Ozawa method [14-17] This iso-conversional integral method, suggested independently by Flynn and Wall and Ozawa, uses Doyle's approximation of the temperature integral. This method is based on equations [8-10]:

$\log \beta=\log \frac{A E}{R g(\alpha)}-2.315-\frac{0.457 E}{R T}$

where decomposition in $\mathrm{kJ}$ mole ${ }^{-1} ; \alpha$, the degree of conversion; $T$, the absolute temperature to reach the conversion and is the integral conversion function.

$g(\alpha)=\int_{0}^{\alpha} \frac{\mathrm{d} \alpha}{f(\alpha)}$

Thus, at a constant conversion ( $\alpha=$ const.), the plot $\log \beta$ versus $(1 / T)$, obtained from a series experiments performed at several heating rates, should be a straight line whose slope allows evaluation of the activation energy:

slope $=\frac{\mathrm{d}(\log \beta)}{\mathrm{d}(1 / T)}=0.4567\left(\frac{E}{R}\right)$

To apply this iso-conversional method, heating rates of 2, 5, 10, 15 and $20^{\circ} \mathrm{C} \min ^{-1}$ were chosen. In this study, 
the conversion values of $5,10,20,30,40,50,60,70,80$ and $90 \%$ have been used, which would give $\alpha$ values 0.05 , $0.1,0.2,0.3,0.4,0.5,0.6,0.7,0.8,0.9$, respectively, for the Flynn-Wall-Ozawa method.

\section{Results}

\section{Thermal properties of silicone rubber}

Depending on the type and concentration of functional terminal groups as well as the amounts of external impurities, the thermal degradation of polysiloxanes can occur according to the following reaction mechanisms [18, 19]:

- Depolymerization according to the mechanism of zip fastener,

- Random splitting of the main chain,

- Dissociation of the $\mathrm{Si}-\mathrm{O}$ bond under the influence of external polar impurities.

Polysiloxanes (PS) containing terminal silane groups ( $\mathrm{Si}-$ $\mathrm{OH})$ or silanol-hydroxy-alkyl groups are depolymerized according to the mechanism of zip fastener.

In the first stage of the polymer heating, its molecular mass sharply increases, which is a result of inter-molecular condensation reactions proceeding between silanol groups on the end of polymer chain and $\mathrm{SiO}$ bond in its main skeleton (Fig. 2). As a result of the reaction of intermolecular regrouping, there are formed low molecular, stable at the PS degradation temperature cyclic siloxanes. The weakest bond in the polysiloxane chain is $\mathrm{C}-\mathrm{Si}$ bond, whose energy amounts to $326 \mathrm{~kJ} \mathrm{~mol}^{-1}$. Cyclic siloxanes are formed as a result of inter-molecular regrouping that is accompanied by the splitting of $\mathrm{Si}-\mathrm{O}$ bond with an energy of $451 \mathrm{~kJ} \mathrm{~mol}^{-1}[19,20]$. In this connection, the thermal degradation process of polysiloxanes can be considered from the point of view of their chemical structure and kinetic parameters and not in terms of the bond energy.

Polysiloxanes containing terminal inert functional groups, most frequently trimethylsilyl, undergo thermal degradation according to the random mechanism. As a result of intra- and inter-molecular reactions proceeding between the random siloxane bond $(\mathrm{SiO})$ occurring in the polymer main chain and its terminal group, starting from the temperature of its thermal decomposition, the molecular mass of polysiloxane sharply decreases, and at the same time, there are formed oligomeric, cyclic siloxane compounds with a high distribution of molecular mass. Polysiloxanes that contain polar ionic impurities, even in low quantities, undergo degradation according to the external catalytic mechanism, consisting in the hydrolytic scission of $\mathrm{Si}-\mathrm{O}$ bond in the polymer main skeleton. The presence of ionic impurities in the reaction medium can sharply deteriorate the thermal properties of polysiloxanes, even within the range of low temperatures [21, 22].

The test results obtained show that the thermal decomposition of the silicone rubber tested proceeds differently under neutral gas and air. The TG curves recorded under nitrogen show a single-stage thermal decomposition of silicone rubber (SR), starting at a temperature of $415^{\circ} \mathrm{C}$. The maximal rate of this process at $T=483{ }^{\circ} \mathrm{C}$ amounts to $22.85 \% \mathrm{~min}^{-1}$ (Fig. 3).

Under air, the polysiloxane tested undergoes at least twostage thermal decomposition (Fig. 3). The first stage already begins at $T=350{ }^{\circ} \mathrm{C}$, while the maximal rate of its decomposition at $T=396{ }^{\circ} \mathrm{C}$ amounts to $3.80 \% \mathrm{~min}^{-1}$, and the other one starts at $T=410^{\circ} \mathrm{C}$, while its maximal rate of decomposition at $T=465{ }^{\circ} \mathrm{C}$ amounts to $16.90 \% \mathrm{~min}^{-1}$.

The two-stage decomposition process of silicone rubber under air can result from catalytic action of oxygen in the depolymerization processes of polysiloxane to volatile cyclic low molecular compounds, as confirmed by a clearly lower temperature of the beginning of thermal decomposition, $T_{\mathrm{R}}$, of SR under air in relation to the value of $T_{\mathrm{R}}$ under nitrogen. The cyclic compounds formed undergo then further thermal decomposition at a temperature above $450{ }^{\circ} \mathrm{C}$, under both air and nitrogen.

The test results obtained show that with increasing the heating rate of silicone rubber, the oxygen diffusion to the boundary zone of sample clearly decreases, while the thermal degradation processes simultaneously become intensified, as confirmed by a clear increase in the temperature of the thermal decomposition beginning, $T_{\mathrm{R}}$ (Fig. 4).

From the studies carried out by Camino et al. [23], it follows that the heating rate clearly also influences the type

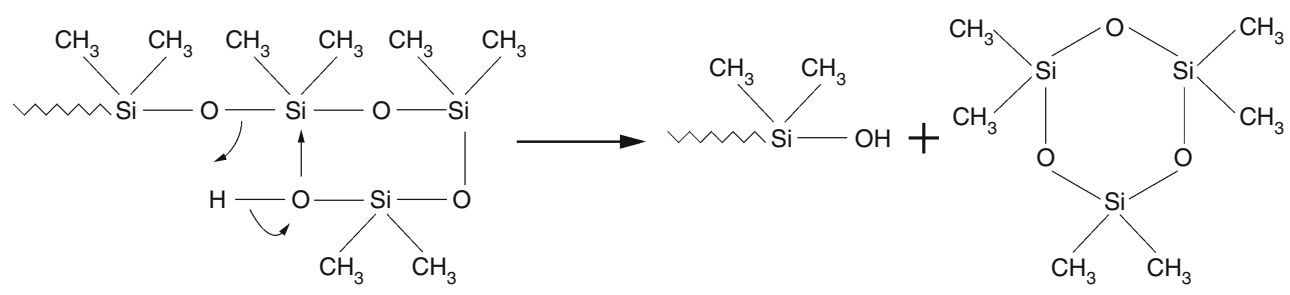

Fig. 2 Inter-molecular mechanism degradation of hydroxyl-terminated polysiloxane 
Fig. 3 TG and DTG curves of silicone rubber in the air and nitrogen atmosphere
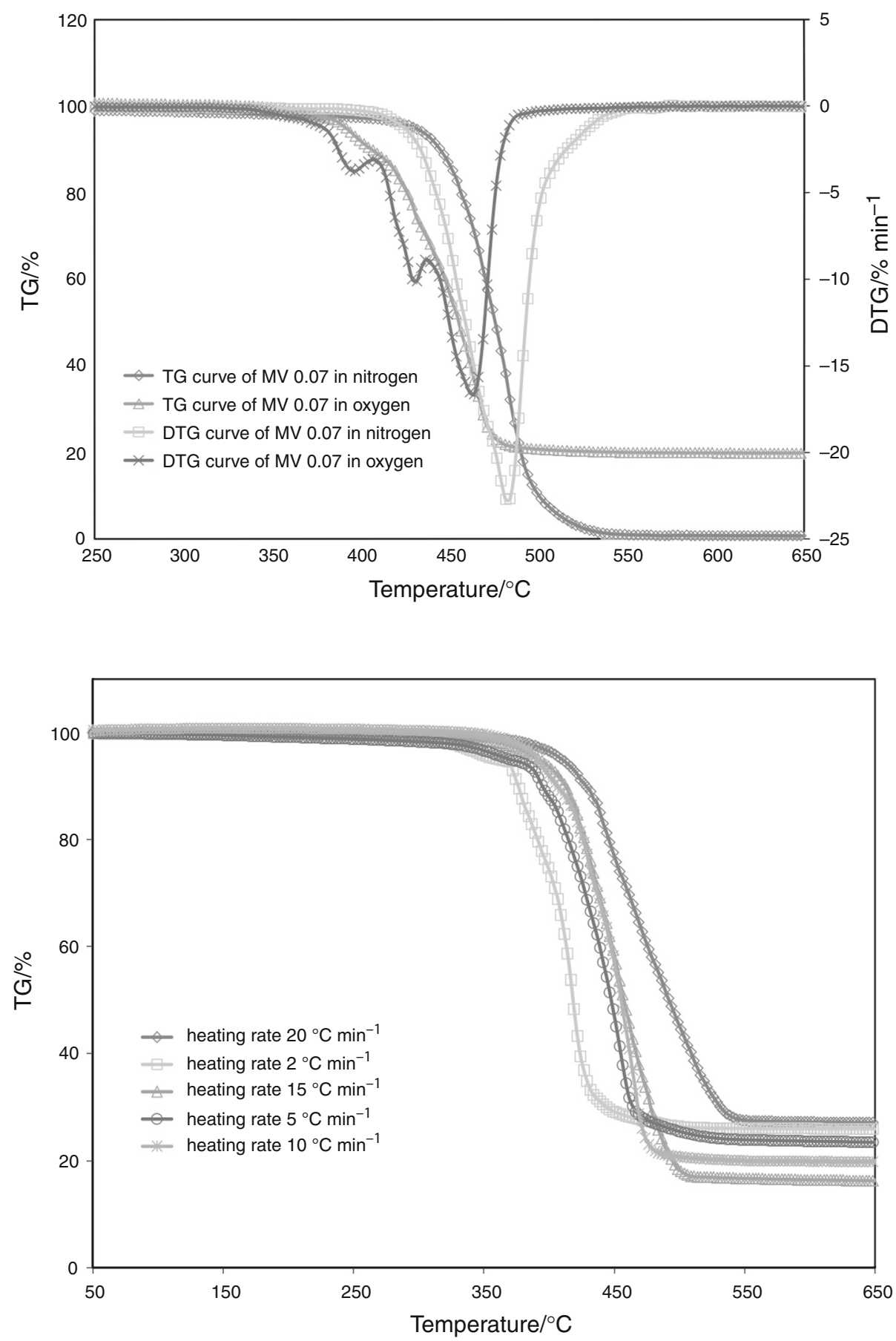

Fig. 4 TG curves of silicone rubber recorded for different heating rates in the air atmosphere of gaseous products resulting from the thermal decomposition of polysiloxane, under both air and nitrogen.

Heating the polymer with a rate not exceeding $10{ }^{\circ} \mathrm{C} \min ^{-1}$ causes that the predominating gaseous products in the mixture of volatile cyclic compounds are trimmers. With increasing the heating rate, their content in the mixture of gaseous products decreases in favor of tetramers, pentamers, hexamers and higher cyclic oligomers.

The activation energy value of the silicone destruction, under both air and nitrogen, was determined with the use of kinetic, non-isothermal Flynn-Wall-Ozawa's method. The activation energy value of the SR destruction under nitrogen amounts to $116.2 \mathrm{~kJ}$ mole ${ }^{-1}$, while that under air amounts to $121.1 \mathrm{~kJ} \mathrm{~mole}^{-1}$ for the first thermal destruction stage and $97.8 \mathrm{~kJ} \mathrm{~mole}^{-1}$ for the second stage (Figs. 4, 5). These values are significantly lower than the value of the Si-O bond energy, which confirms that depolymerization of polysiloxane does not proceed by the hemolytic dissociation of bonds in the polymer main chain, but it results from intramolecular regrouping. The higher destruction activation 
Fig. 5 Thermal decomposition of silicone rubber in the function of its conversion $\alpha$, in the air atmosphere. $\alpha$ in the range $0.05-0.4$, first step of thermal decomposition, $\alpha$ in the range $0.5-0.9$, second step of thermal decomposition
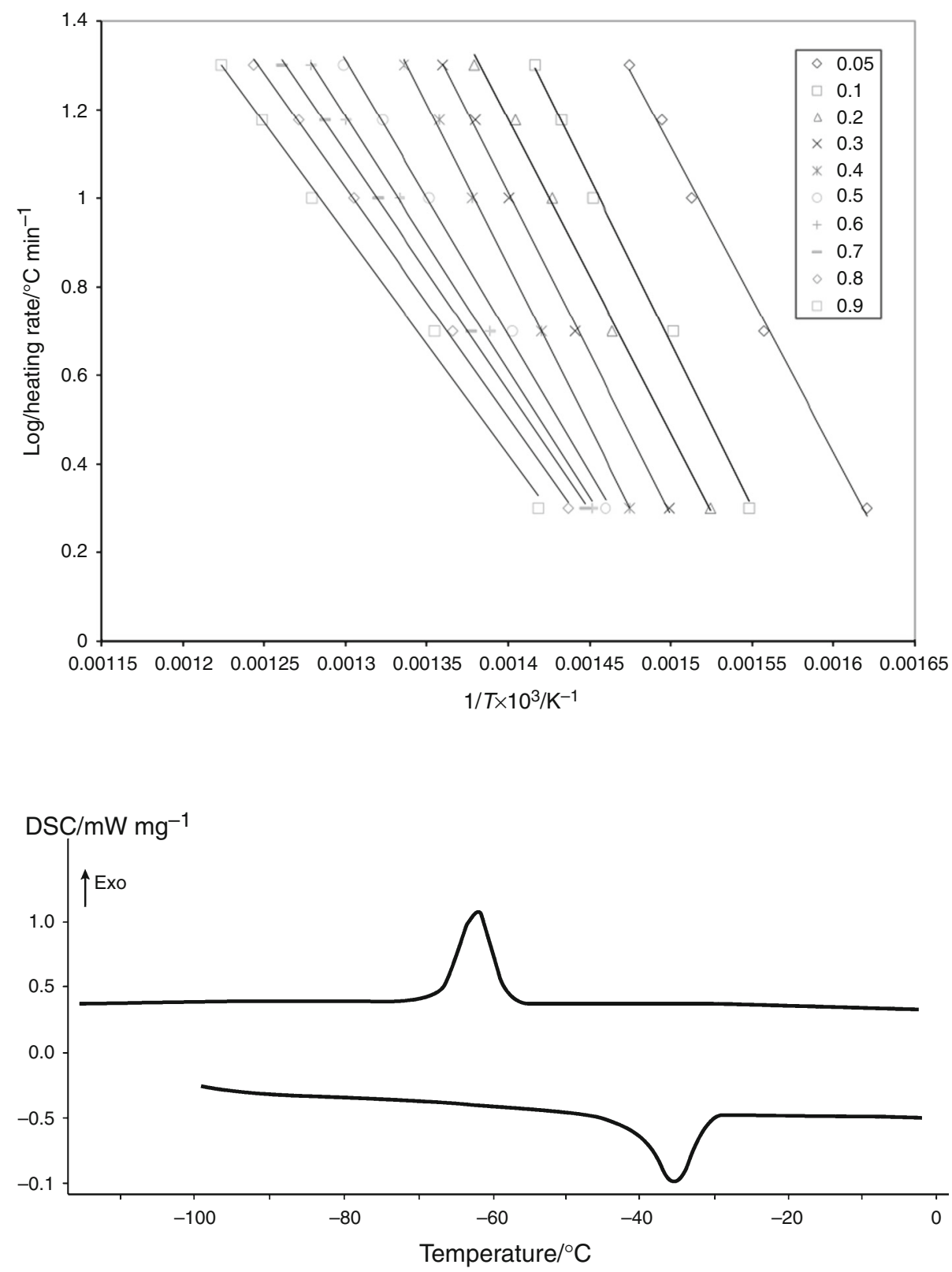

Fig. 6 DSC analysis crosslinked by dicumyl peroxide SR rubber energy under air in the first decomposition stage of silicone rubber decomposition in relation to that in the second stage and also to the corresponding value obtained under nitrogen, probably results from the thermo-oxidative process that stabilizes the boundary layer of SR.

The results obtained by the $D S C$ method show that a high exothermal peak, indicating partial crystallization of polymeric chains, is recorded at $-63{ }^{\circ} \mathrm{C}$ in the curve of SR cooling both before and after its cross-linking with organic peroxide [24]. An endothermic signal indicating the melting of crystalline phase appears in the heating curve at $T=-35.4{ }^{\circ} \mathrm{C}$ (Fig. 6). The $D S C$ analysis performed at $\Delta T=-120$ to $500{ }^{\circ} \mathrm{C}$ did not allow one to determine glass transition temperature $\left(T_{\mathrm{g}}\right) . T_{\mathrm{g}}$ of the rubber tested probably appears at a temperature below $-120{ }^{\circ} \mathrm{C}$.

\section{Characteristic and thermal properties of fillers}

\section{Cenospheres}

The word cenosphere is derived from two Grecian words: kenos (hollow) and sphaira (sphere). Cenospheres are light, chemically neutral, hollow microspheres consisting of silica and alumina, mostly filled with air, obtainable in the process of fine coal combustion $[25,26]$. 
Fig. 7 SEM pictures of fillers a cenospheres, $\mathbf{b}$ cenospheres covered by the iron,

c wollastonite, $\mathbf{d}$ attapulgite,

e silica, $\mathbf{f}$ aluminum hydroxide
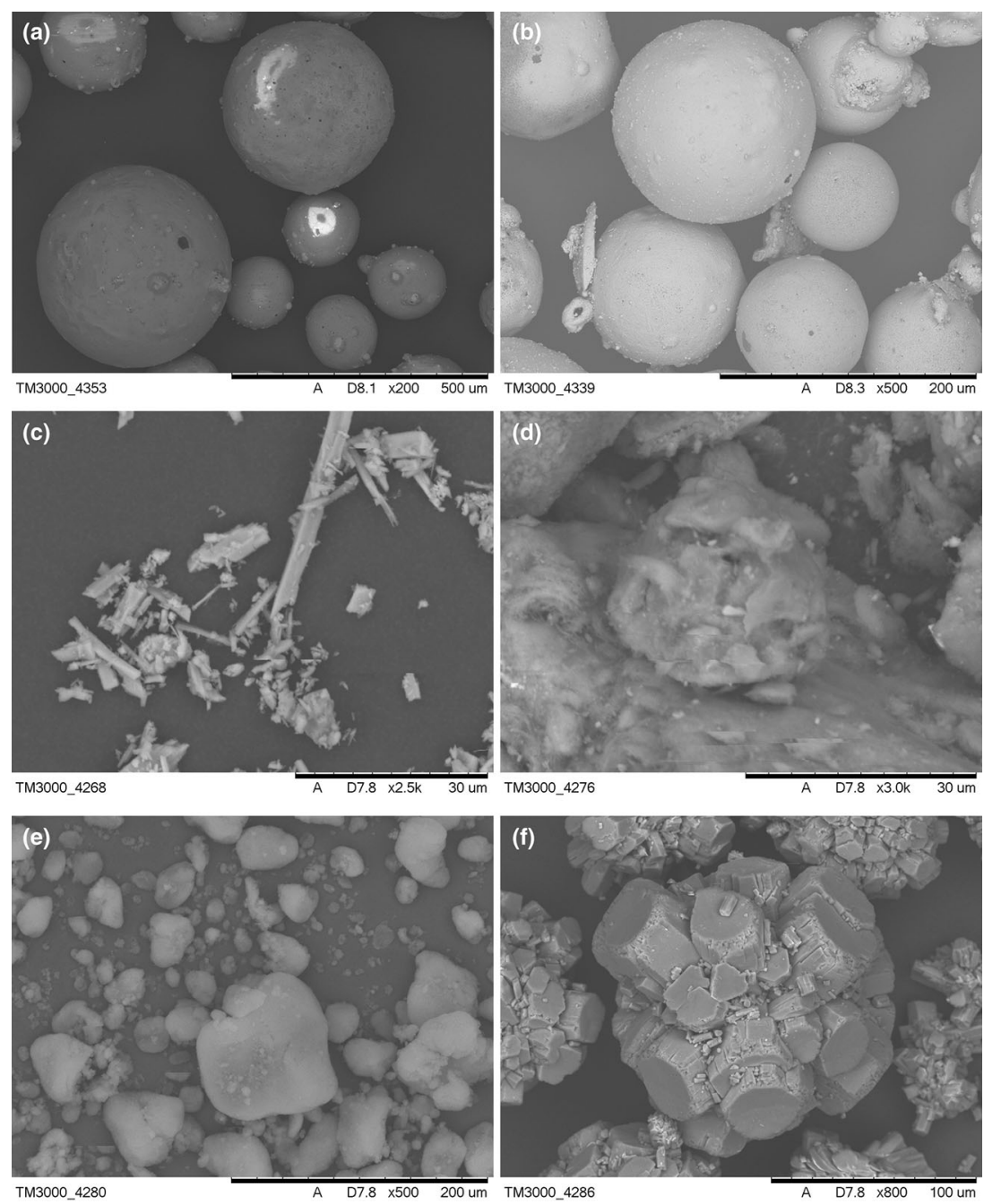

The diameter of cenospheres ranges from 20 to $200 \mu \mathrm{m}$, density from 0.3 to $0.8 \mathrm{~g} \mathrm{~cm}^{-3}$ and wall thickness from 2 to $10 \mu \mathrm{m}$ (Fig. 7a, b).

Cenospheres are characterized by unique properties including a low mass, good insulating properties, low water absorption, high chemical and thermal resistances [27]. From recent literature reports, it follows that cenospheres are more and more frequently used in the production of polymeric composites with a low mass. An addition of cenospheres to poly(vinyl chloride) (PVC) or poly(vinyl acetate) (PVA) allows one to obtain not only light materials but also products with good mechanical and thermal properties [27, 28].

The test results obtained by the method of thermal analysis have shown that cenospheres are thermally stable material, showing no mass loss at $\Delta T=25-700{ }^{\circ} \mathrm{C}$ (Fig. 8).

\section{Wollastonite}

Wollastonite is calcium metasilicate, a mineral occurring in nature in the form of white needle-like anhydrous crystals
(Fig. 7c). The length of wollastonite crystals is at least two times greater than their width, while the shape coefficient of wollastonite (crystal diameter divided by thickness) can be higher than 15 [29].

Wollastonite as cenospheres is a thermally stable material, showing no mass loss at $\Delta T=25-700{ }^{\circ} \mathrm{C}$ (Fig. 8).

\section{Attapulgite}

Attapulgite is fibrous aluminosilicate, with chemical formula: $\mathrm{Mg}_{5}[\mathrm{Al}] \mathrm{Si}_{8} \mathrm{O}_{20}(\mathrm{OH})_{2}-\left(\mathrm{OH}_{2}\right)_{4} \cdot 4 \mathrm{H}_{2} \mathrm{O}$, that is characterized by a high heat capacity and sorption capacity, at a level of 15-30 mval $100 \mathrm{~g}^{-1}$ and as zeolites, shows molecular sieve features [30, 31] (Fig. 7d). This hydrous silicate of magnesium and aluminum is widely used as absorbent, catalytic carrier, disinfection agent, additive to food and drugs and recently as filler of polymers [32]. The structure of attapulgite is three leveled. Single crystals are the smallest structural unit with a length from 500 to $2000 \mathrm{~nm}$ and diameter from 10 to $30 \mathrm{~nm}$. Each single crystal is composed of many laminar units which are tetrahedrons consisting of two connected silicon 
Fig. 8 TG curves of used mineral fillers

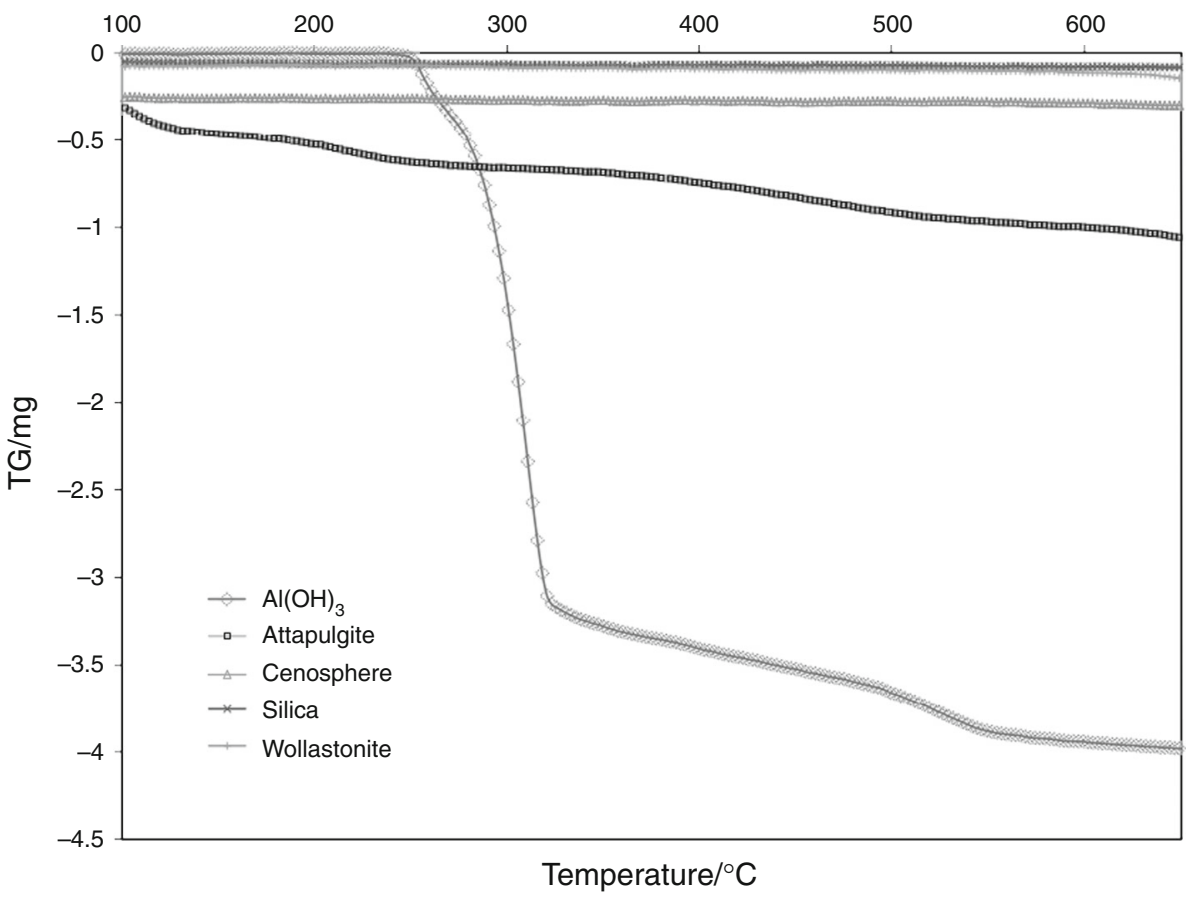

atoms and two oxygen atoms [30-32]. Between neighboring layers are five aluminum atoms tetrahedrally combined with five oxygen atoms. Particular structural units are connected by oxygen atoms to form a crystalline structure in the form of fiber. Individual fibrous crystals are arranged in bundles that are then agglomerated and are seen in a microscale as great solid particles [33].

From the tests performed, it follows that attapulgite (ATT), subjected to TG analysis, undergoes clear fourstaged decomposition at $\Delta T=25-700{ }^{\circ} \mathrm{C}$. The first mass loss amounting to $5.5 \%$, recorded at a temperature below $160{ }^{\circ} \mathrm{C}$, is connected with the release of water physically occluded between fibrous crystals and some water physically combined with the surface of crystals (so-called zeolitic water). The second mass loss observed at $\Delta T=160-320{ }^{\circ} \mathrm{C}$, amounting to $2.9 \%$, corresponds to the release of the remaining zeolitic water. The third mass loss recorded at $\Delta T=320-580{ }^{\circ} \mathrm{C}$, amounting to $3.9 \%$, corresponds to the partial removal of water chemically combined with aluminosilicate (water in the form of hydroxyl groups connected with the surface of ATT). The final mass loss recorded at a temperature above $580{ }^{\circ} \mathrm{C}$ results from the release of the remaining water portion connected with ATT (Fig. 8) [34-36].

\section{Silica}

Silica commercially available occurs in the form of powder obtainable by the flame or precipitation method, and colloid [37] (Fig. 7e). Flame silica is a white, odorless and tasteless amorphous powder formed as a result of hydrothermal process from silicon tetrachloride.

Its characteristic feature is the occurrence, on its surface, of three types of hydroxyl groups, such as insulated, free single silanol groups $\equiv \mathrm{SiOH}$, free geminal silanol or silanodiol groups, $=\mathrm{Si}(\mathrm{OH})_{2}$ and vicinal hydroxyl groups (single silanol or germinal groups connected by hydrogen bonds or both silanol and germinal groups) [38, 39].

Single silanol groups are more active than vicinal silanol groups connected with hydrogen bond, which results from the presence of a reactive hydrogen atom in their structure.

Completely hydrogenated silica contains considerably more combined (vicinal) groups than insulated free silanol groups. Dehydroxylation can decrease the ratio of the combined groups to free silanol groups. On the silica surface are also siloxane bridges $\equiv \mathrm{Si}-\mathrm{O}-\mathrm{Si} \equiv$ that undergo conversion to silanol groups as a result of dehydroxylation.

Silica is the most often used filler incorporated into polysiloxane matrix. Its reinforcing action is connected with the formation of reinforcing bonds between oxygen in the main polymer chain, $\mathrm{Si}-\mathrm{O}-\mathrm{Si}$, and the hydrogen of silanol groups on the silica surface. It should be, however, mentioned that the thermal stability of polysiloxanes in the presence of silica, especially anhydrous silica, usually undergoes a considerable deterioration. This is connected with water physically and chemically combined with the silica surface. At elevated temperature, this water undergoes desorption from the filler surface, catalyzing the decomposition of polysiloxane chain by the hydrolysis of $\mathrm{Si}-\mathrm{O}-\mathrm{Si}$ bond. The thermal analysis of the hydrogenated 
Table 1 Thermal properties of vulcanizates silicone rubber

\begin{tabular}{|c|c|c|c|c|c|c|}
\hline Sample & $T_{5} /{ }^{\circ} \mathrm{C}$ & $T_{50} /{ }^{\circ} \mathrm{C}$ & $\mathrm{d} m / \mathrm{d} t / \% \min ^{-1}$ & $T_{\text {RMAX }} /{ }^{\circ} \mathrm{C}$ & $P \mathrm{w} / \%$ & $P_{650} / \%$ \\
\hline SR DCP & 365 & 471 & 14.15 & 473 & 27.6 & 25.9 \\
\hline SR ATT & 210 & 474 & 4.43 & 452 & 38.3 & 37.5 \\
\hline SR Al & 313 & - & 4.68 & 432 & 55.8 & 55.2 \\
\hline SR SI & 387 & - & 9.42 & 458 & 55.3 & 54.8 \\
\hline SR CE & 394 & - & 5.27 & 507 & 53.1 & 52.6 \\
\hline SR CEFE & 394 & - & 4.57 & 519 & 52.3 & 52.0 \\
\hline SR WO & 435 & - & 9.19 & 445 & 56.5 & 53.4 \\
\hline
\end{tabular}

$S R D C P$ silicone rubber cross-linked by the use of DCP, SR ATT silicone rubber filled by the use of attapulgite, $S R A l$ silicone rubber filled by the use of aluminum hydroxide, $S R S I$ silicone rubber filled by the use of silica, $S R C E$ silicone rubber filled by the use of cenospheres, $S R C E F E$ silicone rubber filled by the use of cenospheres covered iron, $S R$ WO silicone rubber filled by the use of wollastonite

$T_{5}, T_{50}$, temperature of sample 5 and $50 \%$ mass loss, respectively; $\mathrm{d} m / \mathrm{d} t$, maximum rate of thermal decomposition of vulcanizates; $T_{\mathrm{RMAX}}$, temperature of maximum rate of thermal decomposition of vulcanizates; $P \mathrm{w}$, residue after the thermal decomposition of vulcanizates; $P_{650}$, residue after heating to $T=650{ }^{\circ} \mathrm{C}$

silica tested showed that at $\Delta T=25-700{ }^{\circ} \mathrm{C}$, it did not show any mass loss (Fig. 8).

\section{Aluminum hydroxide}

Aluminum hydroxide $\mathrm{Al}(\mathrm{OH})_{3}$ abbreviated $\mathrm{ATH}$ is popular flame retardant and smoke suppressant (Fig. 7f). ATH possesses many advantages: First of all, it is inexpensive, safe in use and easy to incorporate into polymeric materials, even in large quantities. Moreover, it contains in its structure no halides, so its thermal decomposition causes no emission of toxic gases [40, 41].

The flame-retardant effect of ATH is connected with its endothermic decomposition to aluminum oxide and water vapor within a wide range of temperature [42]. The test results obtained by the method of thermal analysis clearly show that ATH undergoes three-staged thermal decomposition at $250-600{ }^{\circ} \mathrm{C}$. The first, free stage of the ATH thermal decomposition occurs at $\Delta T_{1}=250-270{ }^{\circ} \mathrm{C}$. At $\Delta T_{2}=270-345^{\circ} \mathrm{C}$, it undergoes succeeding fast thermal decomposition, as follows from its TG curve. The final, very slow stage of its thermal decomposition is recorded at $\Delta T_{3}=345-550{ }^{\circ} \mathrm{C}$ (Fig. 8). From the review of source literature, it follows that the third stage of ATH thermal decomposition is connected with the presence of insulated hydroxyl groups in its structure, whose thermal decomposition directly depends on their rate of diffusion to the sample boundary layer [43].

\section{Thermal properties of composites silicone rubber}

The test results presented in Table 1 clearly show that the fillers used significantly affect the thermal properties of the silicone rubber filled with them.

Under the influence of attapulgite or aluminum hydroxide, the value of parameter $T_{5}$ of the SR rubber composites tested is distinctly decreased. The decrease in the value of parameter $T_{5}$ in the presence of aluminum hydroxide undoubtedly results from its endothermic decomposition with the simultaneous release of water vapor that decreases the amounts of fuel and oxygen diffuse rate to the flame. It is, however, possible that between water vapor and the polymer, thermal decomposition products proceed strong endothermic interactions that contribute to decreasing the flame temperature. Undoubtedly, a great influence on the flame-retardant capability of aluminum hydroxide is exerted by the aluminum oxide formed due to the endothermic decomposition of the former. This oxide, becoming a part of the boundary layer composition, on account of its high heat capacity, significantly contributes to a reduction in mass transport, especially energy transport between sample and flame.

It should be noticed that in the presence of attapulgite, the decomposition rate of silicone rubber is the lowest from among all the filler tested.

The mechanism of mutual polymer-filler interaction is very complex and has not been yet adequately explained; nevertheless, it may be concluded that the decrease in the thermal decomposition rate of the filler-containing silicone rubber vulcanizates tested in relation to the initial sample can be due to an increase in the polymer chain immobilization around the filler particles.

The thermal decomposition residue, determined with parameter $P \mathrm{w}$, exerts a significant effect on the flammability of polymeric materials. An increase in this parameter causes that the quantity of destruction products passing to flame becomes lower.

The presence of each filler used contributes to an increase in the value of parameter $P \mathrm{w}$, while the highest thermal decomposition residue is recorded for wollastonite. It is also worth noticing that under the influence of this filler, the cross-linked silicone rubber is characterized by the greatest thermal stability expressed with parameter $T_{5}$. 
From the review of literature, it follows that wollastonite, incorporated in a quantity lower than five parts by mass into the rubber matrix, does not contribute to the formation of the insulating boundary layer. The maximal quantity of wollastonite incorporated into the silicone rubber matrix directly depends on the required final properties of the product obtained. However, it should be mentioned that the incorporation of wollastonite in a quantity higher that 70 parts by mass results in a material with a very high rigidity and brittleness, which makes it impossible to use it, e.g., for the production of electric insulations [3].

A considerable increase in the value of parameter $P \mathrm{w}$ and the residue after thermal decomposition at a temperature of $650{ }^{\circ} \mathrm{C}$ is recorded for the vulcanizate filled with silica.

Undoubtedly, silica considerably affects the boundary layer structure of the vulcanizate under combustion. Nevertheless, according to Kashiwagi, a decreased flammability of the polymer-silica composite is largely connected with the physical processes proceeding in condensed phase than chemical reactions in the gaseous phase. Of paramount importance is the equilibrium between the silica density and specific surface and the viscosity of the melted polymer, since it depends on this equilibrium whether silica is cumulated near the surface of the sample burned or is immersed in the melted polymer mass [44].

A significant increase in the thermal stability of the silicone rubber vulcanizates was recorded when these were filled with cenosphere. In the presence of this innovative filler, not only the parameter $T_{5}$ is considerably increased and the parameter $\mathrm{d} m / \mathrm{d} t$ (thermal destruction intensity) is decreased, but also the temperature of the maximal decomposition rate, $T_{\mathrm{RMAX}}$, is shifted toward higher temperature, especially when cenosphere is coated with iron.

The effect of metal with variable valence on the thermal stability of polymeric materials has not been adequately explained. From the review of literature, it follows that cobalt compounds dramatically decrease the thermal stability of the silicone rubber vulcanizates [45]. Cobalt, through the transfer of electron in the subshell 3d, generates a high number of macroradicals [46], initiating the thermal decomposition of SR as well as PE or PP. It should be, however, clearly underlined that other transition metal such as $\mathrm{Ni}$ or $\mathrm{Fe}$ that potentially could take part in the initiation of radical reaction, contrary to cobalt, is characterized by a low catalytic activity. From literature reports and the test performed, it follows that the maximal decomposition rate of silicone rubber, containing iron or nickel atoms, occurs at a temperature over $500{ }^{\circ} \mathrm{C}$ so, at a temperature higher by more than $30{ }^{\circ} \mathrm{C}$ than that of unfilled silicone rubber. Thus, it is possible that metals with variable valence facilitate the stabilization of boundary layer.
Table 2 The results obtained by the DSC method vulcanizates of silicone rubber

\begin{tabular}{lcc}
\hline Sample & $T_{\mathrm{c}} /{ }^{\circ} \mathrm{C}$ & $T_{\mathrm{m}} /{ }^{\circ} \mathrm{C}$ \\
\hline SR DCP & -63.0 & -35.4 \\
SR ATT & -63.6 & -34.7 \\
SR Al & -69.7 & -37.4 \\
SR SI & -62.2 & -37.9 \\
SR CE & -64.7 & -36.8 \\
SR CEFE & -60.6 & -32.9 \\
SR WO & -59.0 & -32.8 \\
\hline
\end{tabular}

$T_{\mathrm{c}}$ crystallization temperature, $T_{\mathrm{m}}$ crystallites melting temperature

From the analysis of results obtained by the DSC method, it follows that its not a clear influence of the used fillers on the value of crystallization and fusion temperature of the crystalline phase of the silicone rubber composites tested (Table 2).

Under the influence of aluminum hydroxide, the values of $T_{\mathrm{c}}$ and $T_{\mathrm{m}}$ temperatures clearly shift toward lower temperatures, which are probably connected with a high content of water combined in the composite. Under the influence of wollastonite and cenosphere coated with iron, the crystallization and fusion temperatures of crystalline phase are shifted toward higher values.

\section{Conclusions}

The thermal decomposition of the silicone rubber tested under inert gas (nitrogen) proceeds differently from that under air. Under air, the polysiloxane tested undergoes at least two-staged thermal decomposition. The first stage is connected with the catalytic effect of oxygen in the processes of its depolymerization, while the second stage with the decomposition of low molecular destruction products is formed during the first stage of its thermal decomposition.

The destruction activation energy values, under both air and nitrogen, are decisively lower than the value of the $\mathrm{Si}-$ $\mathrm{O}$ bond energy, which confirms the fact that the depolymerization of polysiloxane does not proceed by the homolytic dissociation of bonds in the main polymer skeleton, but results from internal molecular regrouping.

The mineral fillers used clearly affect the thermal properties of cross-linked silicone rubber. A distinct increase in the thermal stability of SR vulcanizate was recorded for vulcanizates filled with cenosphere. In the presence of this filler, a significant increase in the value of parameter $T_{5}$ and a decrease in the value of parameter $\mathrm{d} m / \mathrm{d} t$, showing the intensity of thermal destruction, are observed. Moreover, under the influence of cenospheres, especially those coated with iron, the temperature of the maximal decomposition rate, $T_{\text {RMAX }}$, is shifted toward higher temperature values in relation to unfilled vulcanizate. 
The thermal decomposition residue (parameter $P \mathrm{w}$ ) exerts a considerable impact on the flammability of polymeric materials. An increase in the value of this parameter causes that the quantity of the destruction products passing to flame is lower.

In the presence of each of all the fillers used, the value of parameter $P \mathrm{~W}$ increases, while the highest value of $P \mathrm{~W}$ was recorded for the vulcanizate containing wollastonite. It is also worth noticing that under the influence of this filler, the cross-linked silicone rubber is characterized by the highest thermal stability expressed with parameter $T_{5}$.

The significant, positive influence of the innovative cenospheric filler on the thermal properties of silicone rubber allows one to believe that this filler will also show a positive effect on the reduction in flammability of vulcanizates containing it. Taking into account the fact that polymeric materials filled with cenospheres are characterized by good mechanical properties and a significantly lower mass in relation to polymers filled with silica, one can assume that this type of filler will be more and more frequently used for the production of polymeric materials exploited in various branches of industry, such as automotive or aircraft industry.

Open Access This article is distributed under the terms of the Creative Commons Attribution 4.0 International License (http://creativecommons.org/licenses/by/4.0/), which permits unrestricted use, distribution, and reproduction in any medium, provided you give appropriate credit to the original author(s) and the source, provide a link to the Creative Commons license, and indicate if changes were made.

\section{References}

1. Rybiński P, Janowska G, Kucharska-Jastrząabek A, Pająk A, Wójcik I, Wesołek D, Bujnowicz K. Flammability of vulcanizates of diene rubbers. J Therm Anal Calorim. 2012;107(3): 1219-24.

2. Rybiński P, Janowska G, Plis A. Thermal properties and flammability of ethylene-vinyl acetate rubbers (EVM) and their cross-linked blends with nitrile rubber (NBR). Thermochim Acta. 2013;568:104-14.

3. Handani S, Longuet C, Perrin D, Lopez-Cuesta J-M, Ganachaud F. Flame retardancy of silicone-based materials. Polym Degrad Stab. 2009;94:465-95.

4. Bouch RR. Rates of heat release and related fire parameters for silicones. Fire Safety. 1991;17:1-12.

5. Hshieh F-Y. Shielding effects of silica ash layer on the combustion of silicones and their possible applications on the fire retardancy of organic polymers. Fire Mater. 1998;22:69-76.

6. Biron M. Silicones or siloxanes applications. Techniques de I'Ingenieur Oct 2007; N2882.

7. Heiner J, Stenberg B, Persson M. Polym Test. 2003;22:253-7.

8. Hamolani S, Longuet C, Lopez-Cuesta J-M, Ganachaud F. Calcium and aluminum-based fillers as flame-retardant additives in silicone matrices. I. Blend preparation and thermal properties. Polym Degrad Stab. 2010;95:1911-9.
9. Demir MM, Menceloglu YZ, Erman B. Effect of filler amount on thermoplastic properties of poly(dimethylsiloxane) networks. Polymer. 2005;46:4127-34.

10. Arrighi V, Higgins JS, Burgess AN, Floudas G. Local dynamics of poly(dimethyl siloxane) in the presence of reinforcing filler particles. Polymer. 1998;39:6369-76.

11. Kozakiewicz J, Huang SJ. The effects of filler surface modifications on the properties of poly(dimethyl siloxane) elastomers. Org Coat Plast Chem. 1981;44:343-6.

12. Meng X-F, Shen X-Q, Liu W. Synthesis and characterization of Co/cenosphere core-shell structure composites. Appl Surf Sci. 2012;258:2627-31.

13. Sun JT, Huang YD, Gong GF, Cao HL. Thermal degradation kinetics of poly(methylphenylsiloxane) containing methacryloyl groups. Polym Degrad Stab. 2006;91:339-46.

14. Ozawa T. A new method of analyzing thermogravimetric data. Bull Chem Soc Jpn. 1965;38:1881-6.

15. Flyn JH, Wall LA. A quick direct method for determination of activation energy from thermogravimetric data. J Polym Sci Polym Lett. 1966;4:323-8.

16. Dowdy DR. Meaningful activation energies for complex systems. The application of the Ozawa-Flynn-Wall method to multiple reactions. J Therm Anal. 1987;32(1):137-47.

17. Rybiński P, Janowska G, Dobrzyńska R, Kucharska A. Effect of halogenless flame retardants on the thermal properties, flammability and fire hazard of cross-linked EVM/NBR rubber blends. J Therm Anal Calorim. 2014;115:771-82.

18. Dvornic PR. In: Jones RG, Ando W, Chojnowski J, editors. Thermal stability of polysiloxanes: silicone-containing polymers. Dordrecht: Kluwer Academic Publisher; 2000. p. 185-212.

19. Jovanovic JD, Govedarica MN, Dvornic PR, Popovic IG. The thermogravimetric analysis of some polysiloxanes. Polym Degrad Stab. 1998;61:87-93.

20. Camino G, Lomakin SM, Lazzari M. Polydimethylsiloxane thermal degradation. Part 1. Kinetic aspect. Polymer. 2001;42: 2395-402.

21. Grassie N, Macfarlane IG. The thermal degradation of polysiloxane-poly(dimethylsiloxane). Eur Polym J. 1978;14:875-84.

22. Deshpande G, Rezac ME. Kinetic aspects of the thermal degradation of poly(dimethylsiloxane) and poly(dimethyl diphenyl siloxane). Polym Degrad Stab. 2002;76:17-24.

23. Camino G, Lomakin S, Lageard M. Thermal polydimethylsiloxane degradation Part 2. The degradation mechanism. Polymer. 2002;43(7):2011-5.

24. Rey T, Chagnon G, Le Cam J-B, Favier D. Influence of the temperature on the mechanical behaviour of filled and unfilled silicone rubbers. Polym Test. 2013;32:492-501.

25. Kolay PK, Bhusal S. Recovery of hollow spherical particles with two different densities from coal fly ash and their characterization. Fuel. 2014;117:118-24.

26. Kolay PK, Singh DN. Physical, chemical, mineralogical and thermal properties of cenospheres from an ash lagoon. Cem Concr Res. 2001;31:539-42.

27. Yih SM, Tu CH, Kuo ST, Quo LW. Recovery of cenospheres and application to the manufacture of insulation materials. J Chin Inst Chem Eng. 1998;19(1):23-9.

28. Ngu LN, Wu H, Zhang DK. Characterization of ash cenospheres in fly ash from Australian power station. Energy Fuels. 2007;21(6):3437-45.

29. Singh B, Gupta M, Verma A. Polyester moulding compounds of natural fibers and wollastonite. Compos A. 2003;34:1035-43.

30. Bradley WF. The structural scheme of attapulgite. Am Miner. 1940;24:405-10.

31. Sun L-H, Yang Z-G, Li X-H. Effects of the treatment of attapulgite reinforced fabric composites. Compos A. 2009;40:1785-91. 
32. Tian M, Qu Ch, Feng Y, Zhang L. Structure and properties of fibrillar silicate/SBR composites by direct blend process. J Mater Sci. 2003;38:4917-24.

33. Wang L, Sheng J. Preparation and properties of polypropylene/ org-attapulgite nanocomposites. Polymer. 2005;46:1785-91.

34. Cao E, Bryant R, Williams DJA. Electrochemical properties of Na-attapulgite. J Colloid Interface Sci. 1996;179:143-50.

35. Tian M, Liang W, Rao G, Zhang L, Guo C. Surface modification of fibrillar silicate and its reinforcing mechanism on FS/rubber composites. Compos Sci Technol. 2005;65:1129-38.

36. Rybiński P, Janowska G, Jóźwiak MA, Jóźwiak M. Thermal stability and flammability of styrene-butadiene rubber (SBR) composites. J Therm Anal Calorim. 2013;113:43-52.

37. Bikiaris DN, Vassiliou AA. Current status and promises in environmental biodegradation research focus. In: Wang BY, editors. Fumed silica reinforced nanocomposites. New York: Nova Publishers; 2008. p. 189-215 (chapter 7).

38. Sindrof DW, Maciel GE. Cross-polarization magic-angle-spinning silicon-29 nuclear magnetic resonance. Study of silica gel using trimethylsilane bonding as a probe of surface geometry and reactivity. J Phys Chem. 1982;86:5208-19.

39. Zhuravlev LT, Potapov VV. Density of silanol groups on the surface of silica precipitated from hydrothermal solution. Rus J Phys Chem. 2006;80(7):1119-28.
40. Lynch TJ, Chen T, Riley D. Advances in ATH benefit composite products. Reinforc Plast. 2003;9:44-6.

41. Rybiński P, Janowska G. Effect of flame retardants on thermal stability and flammability of cured nitrile rubber. Polimery. 2009;54:833-9.

42. Troitzsch HJ. In: Gachter R, Muller H, editors. Flame retardants: plastics additives. Cincinnati: Hanser Publisher; 1993. p. 709-748.

43. Hancock M. In: Rothon R, editor. Principal types of particulated fillers: particulate-filled polymer composites. 2nd ed. Rapra Technol Limited: United Kingdom; 1995. p. 85-8.

44. Kashiwagi T, Gilman JW, Butler KM, Harris RH, Shields JR, Asano A. Flame retardant mechanism of silica gel/silicas. Fire Mater. 2000;94:465-95.

45. Li Z, Lin W, Moon K-S, Wilkins SJ, Yao Y, Watkins K, Morato $\mathrm{L}$, Wong $\mathrm{Ch}$. Metal catalyst residues in carbon nanotubes decrease the thermal stability of carbon nanotube/silicone composites. Carbon. 2011;49:4138-48.

46. Roy PK, Surekha P, Rajagopal C, Chatterjee SN, Choudhary V. Effect of benzil and cobalt stearate on the aging of low-density polyethylene films. Polym Degrad Stab. 2005;90(3):577-85. 